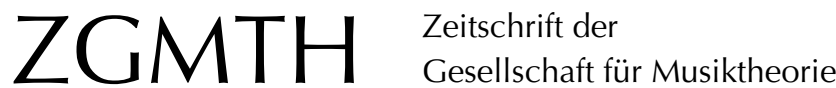

Gies, Stefan (2011): Musiktheorie als pädagogisch bedeutsames Fach. ZGMTH 8/1, 17-18. https://doi.org/10.31751/609

\section{(C) 2011 Stefan Gies}

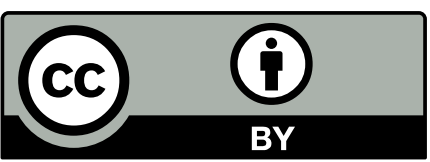

Dieser Text erscheint im Open Access und ist lizenziert unter einer Creative Commons Namensnennung 4.0 International Lizenz.

This is an open access article licensed under a

Creative Commons Attribution 4.0 International License.

veröffentlicht / first published: 14/06/2011

zuletzt geändert / last updated: 06/06/2013 


\title{
Musiktheorie als pädagogisch bedeutsames Fach
}

\author{
Stefan Gies
}

Einem an Musikhochschulen verbreiteten Verständnis zufolge tritt Musiktheorie heute vor allem als ein auf Praxis gerichtetes Deutungssystem in Erscheinung. In diesem Sinne ist sie mehr Lehre als Theorie und weitgehend frei von mathematischen, ontologischen oder auch mystischen Implikationen. Das war nicht immer so, und das muss auch nicht zwangsläufig immer so bleiben.

Als Lehre von der strukturellen Beschaffenheit der Musik steht Musiktheorie zu den Musikwerken in einem ähnlichen Verhältnis wie Grammatik zur Sprache. Im günstigsten Fall gelingt es beiden - der Musiktheorie ebenso wie der Grammatik - eine gegebene Praxis systematisierend zu beschreiben ohne den Anspruch zu erheben normierend in diese Praxis einzugreifen. Und genau so wie das Mitglied einer Sprachgemeinschaft nicht notwendigerweise über Kenntnisse der Grammatik im Sinne eines abrufbaren Regelsystems bewusst verfügen muss, um dieses korrekt anzuwenden, so ist auch musikalische Praxis nicht darauf angewiesen, dass die diese Praxis hervorbringenden Musiker auf Musiktheorie Bezug nehmen.

Musiktheorie macht das Systematische einer in sich immer auf irgendeine Weise systematischen Musikpraxis anschaulich, indem sie dieses Systematische auf die Ebene der Begrifflichkeit hebt. Das ist die eigentliche Stärke der Musiktheorie, und das legitimiert das Fach auch als bedeutsames Fach innerhalb des Schulmusikstudiums. Für einen Lehrer $^{1}$, der sich zum Ziel gesetzt hat, einen Schüler in einer Fremdsprache kommunikationsfähig zu machen, ist es hilfreich und sinnvoll, wenn er über gute Kenntnisse des grammatischen Regelsystems dieser Sprache verfügt. Das erleichtert ihm die didaktische Strukturierung des von ihm bereitgestellten Lernangebotes und kann wesentlich dazu beitragen, dieses Lernangebot effizient zu gestalten. Der Schüler aber, dem es um den Erwerb von Kompetenzen in der Anwendung der von ihm zu lernenden Sprache in Kommunikationssituationen geht, kann dieses Ziel auch erreichen ohne sich allzu viele Grammatikregeln bewusst zu machen. Dass Musiktheorie das Regelwerk einer systematischen Musikpraxis auf der Ebene der Begrifflichkeit abbildet, macht sie zu einem pädagogisch bedeutsamen Fach, ich würde sogar sagen: zu einem vor allem anderen pädagogisch bedeutsamen Fach.

1 Maskuliner Genus bezieht sich hier und im Folgenden stets auch auf femininen Sexus. 
Als sich gegen Ende meiner Schulzeit die Frage stellte, ob ich denn und was ich denn nun studieren wolle, konnte ich auf umfangreiche und breit gefächerte musikpraktische Erfahrungen zurückgreifen. Musikmachen und Musikhören waren für mich zentrale Interessensgebiete. All das hätte aber nicht ausgereicht, um die Aufnahme eines Musikstudiums in Erwägung zu ziehen. Der maßgebliche Impuls für meine Entscheidung, Musik und Musikpädagogik zum Beruf zu machen ging von meinem kurz vor dem Abitur erwachenden Interesse für Musiktheorie aus. Fasziniert war ich von der Musiktheorie - deren Fragestellungen für mich damals vollkommen neu waren -, weil sie mir die schlüssigsten Antworten auf die für mich existentielle Frage lieferte, was mich denn eigentlich an der Musik so sehr interessiert, dass ich sie zu meinem Lebensinhalt machen will.

Auch an der Hochschule, an der ich jetzt für die musikdidaktische Ausbildung verantwortlich bin, geht für viele Studierende eine große Faszination von der Musiktheorie aus. Das ist gut so, denn diese - nicht zuletzt durch charismatische Lehrer beförderte - Faszination hilft, die Studierenden mit dem notwendigen Grundlagenwissen auszurüsten, auf das sie als Lehrer in der Erarbeitung eines breiten, vielfältigen und differenzierten didaktischen Repertoires immer wieder zurückgreifen müssen. Problematisch bleibt, dass es viel zu vielen Schulmusikabsolventen nicht gelingt, zusammen mit dem Rollenwechsel vom Studenten zum Lehrer auch die Rolle der Musiktheorie für sich neu zu bestimmen. Wenn sie das nicht tun, kann es passieren, dass sie in der Schule nicht Musik unterrichten, sondern Musiktheorie. Und das schadet sowohl dem Musikunterricht als auch der Musiktheorie. Dem entgegenzusteuern sollte als gemeinsame Aufgabe von Musikpädagogik und Musiktheorie begriffen werden. 